\title{
Determining the protective characteristics and risk factors for the development of anastomotic leakage after low anterior resection for rectal cancer
}

\author{
Nobuaki Suzuki ${ }^{1}$. Shin Yoshida ${ }^{1}$. Shinobu Tomochika ${ }^{1}$ Yuki Nakagami ${ }^{1,2} \cdot$ Yoshitaro Shindo $^{1} \cdot$ Yukio Tokumitsu $^{1}$. \\ Michihisa lida ${ }^{1} \cdot$ Shigeru Takeda $^{1} \cdot$ Shoichi Hazama ${ }^{1,2} \cdot$ Tomio Ueno $^{3} \cdot$ Hiroaki Nagano ${ }^{1}$
}

Received: 22 June 2020 / Accepted: 20 August 2020 / Published online: 2 October 2020

(c) The Author(s) 2020

\begin{abstract}
Purpose Anastomotic leakage is one of the most serious postoperative complications associated with surgery for rectal cancer. The present study aimed to identify the protective characteristics and risk factors associated with anastomotic leakage after low anterior resection for rectal cancer.

Methods This was a retrospective, single-center study conducted between January 2009 and December 2017 at our institution. In total, 136 rectal cancer patients who underwent low anterior resection were included in the study. We analyzed preoperative and intraoperative factors. In addition, the pelvic dimensions were measured using computed tomography in all cases. Results Among the 136 patients, anastomotic leakage occurred in 21 (15.4\%), including 18 males and 3 females. The median body mass index was $21.1 \mathrm{~kg} / \mathrm{m}^{2}$. The construction of a covering stoma was found to be a protective factor. In addition, the operation time $(\geq 373 \mathrm{~min})$, intraoperative blood loss $(\geq 105 \mathrm{ml})$, and size of the pelvic inlet $(\geq 113 \mathrm{~mm})$ were identified as risk factors for anastomotic leakage.

Conclusion The construction of a covering stoma was a possible protective factor. However, a longer operation time, higher intraoperative blood loss, and larger pelvic inlet dimensions were possible risk factors for developing anastomotic leakage after low anterior resection in patients with rectal cancer.
\end{abstract}

Keywords Colorectal surgery $\cdot$ Anastomotic leak $\cdot$ Risk factor $\cdot$ Rectal cancer $\cdot$ Pelvic index

\section{Introduction}

Advances in surgical procedures and adjuvant therapies have made sphincter-preserving surgery the standard operation for most patients with rectal cancer. Heald et al. introduced a new method called total mesorectal excision (TME) for the treatment of rectal cancer. TME as a novel surgical method is important for preventing injury to the fascia propria of

Hiroaki Nagano

hnagano@yamaguchi-u.ac.jp

1 Department of Gastroenterological, Breast and Endocrine Surgery, Yamaguchi University Graduate School of Medicine, Ube, Japan

2 Department of Translational Research and Developmental Therapeutics Against Cancer, Yamaguchi University School of Medicine, Ube, Japan

3 Department of Digestive Surgery, Kawasaki Medical School, Kurashiki, Japan the rectum. At present, this technique is considered the gold standard for managing rectal cancer surgery [1-3].

Anastomotic leakage (AL) is a postoperative complication that occurs in patients who undergo low anterior resection (LAR) for rectal cancer [4-6]. AL leads to several serious postoperative complications, including peritonitis, sepsis, need for re-operation or percutaneous intervention, prolonged hospitalization, increased medical costs [7-9], and a poor prognosis $[10,11]$. The basic requirements for anastomotic healing are proper healthy bowel ends and tension-free anastomosis [12]. Previously reported risk factors for AL during surgery include the operation time, amount of intraoperative blood loss, and blood transfusion [13, 14]. Tsuruta et al. reported that a smaller ratio of the difference between the interspinous distance and diameter of the mesorectum to the depth of the lesser pelvic cavity (pelvic index) was associated with a higher risk of AL [15]. Similarly, a few studies have reported the detection of risk factors for AL using preoperative imaging findings [16, 17]. However, 
there is currently no consensus regarding the risk factors associated with AL.

The present study, therefore, explored the protective as well as risk factors for AL by analyzing preoperative and intraoperative features on preoperative reconstructed coronal and sagittal computed tomography (CT) images.

\section{Methods}

\section{Study population}

A total of 186 patients with rectal cancer who consecutively underwent surgery at the Department of Gastroenterological, Breast and Endocrine Surgery, Yamaguchi University Graduate School of Medicine, between January 2009 and December 2017, were enrolled. Among those patients, 50 were excluded, because they underwent surgery using other methods (Miles' operation, $n=16$; Hartmann's operation, $n=8$; total pelvic extirpation, $n=3$; transanal operation, $n=17$; and others, $n=6$ ). A total of 136 patients with primary rectal cancer were finally included in this study (Fig. 1). Preoperative chemotherapy or chemoradiotherapy was administered for complex cases, such as bulky tumors or tumors with extramural invasion [18]. Ten patients underwent preoperative chemotherapy, and two patients underwent chemoradiotherapy (Table 1).

We examined the following variables that represented protective and risk factors for AL: sex, age, body mass index (BMI), tumor location (upper rectum [Ra] or lower rectum [Rb]), neutrophil-to-lymphocyte ratio (NLR), lymphocyteto-monocyte ratio (LMR), serum albumin (Alb), UICC-T factor, UICC-stage, diverting stoma construction, use of an intraluminal drain, operating time, intraoperative blood loss, tumor size, and laparotomy. The clinical stage was classified preoperatively according to the UICC-TNM classification ( $8^{\text {th }}$ edition) and confirmed by postoperative histopathological examination findings.

The study was conducted in accordance with the ethical standards laid down in the 1964 Declaration of Helsinki and its later amendments and the ethical guidelines for clinical studies. The study protocol was approved by the institutional review board of Yamaguchi University (H28-186).

\section{Surgical technique}

The standard surgical technique for most patients was laparoscopic low anterior resection, except for a few patients who underwent open midline laparotomy. Ligation and resection of the inferior mesenteric artery and vein were performed, followed by TME. Intersphincteric resection was

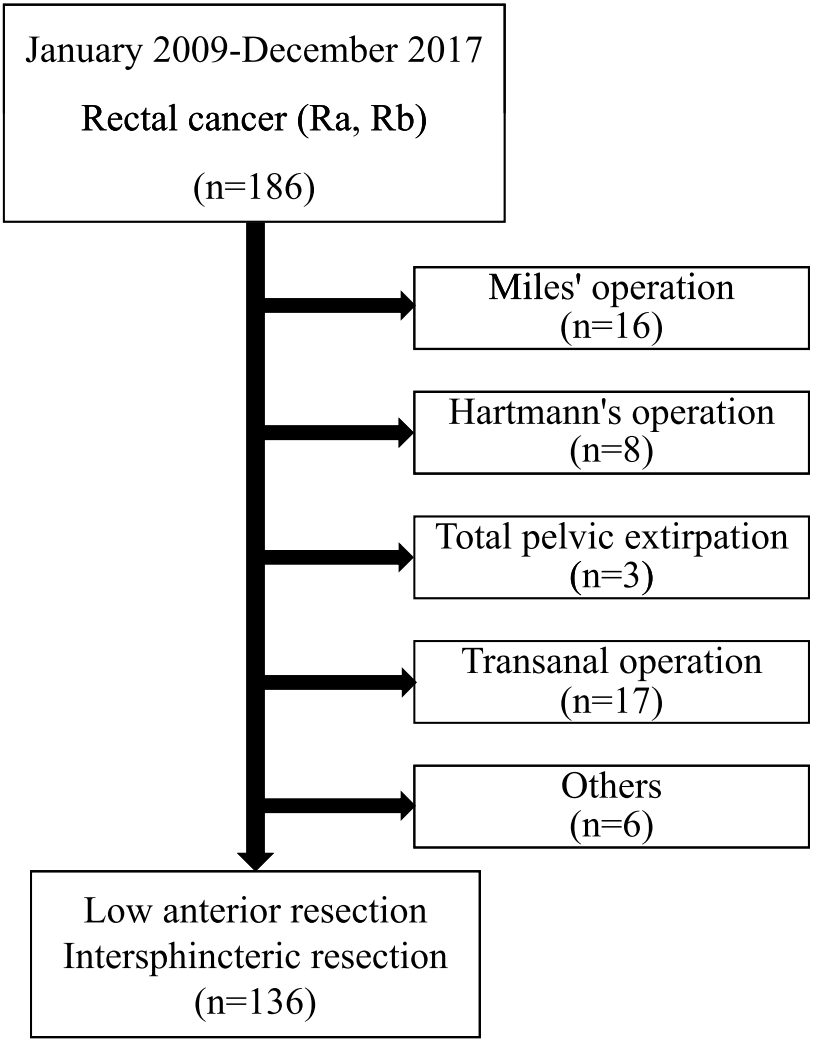

Fig. 1 CONSORT diagram. This was a retrospective, single-institution study of 136 patients with rectal cancer $(\mathrm{Ra}, \mathrm{Rb})$ who underwent low anterior resection with the double stapling technique or handsewn anastomosis between January 2009 and December 2017 at our institution

carried out for very low rectal tumors. Bilateral lymph node dissection was performed in cases, where the main tumor location was lower than $\mathrm{Rb}$ and the invasion depth was deeper than T3 [19]. The double stapling technique (DST) or handsewn anastomosis type of neorectal reconstruction was performed. A temporary stoma was created at the surgeons' discretion. A transanal drain was inserted in all patients in the latter half of the study period.

\section{Measurements of the pelvis}

A pelvic CT examination was performed in all patients as a part of the routine preoperative work-up for rectal surgery. Using reconstructed coronal and sagittal CT images, a few examiners who were blinded to the patients' information evaluated the following dimensions of the pelvis: $\mathrm{a}=$ length of the lateral pelvis, $b=$ length of the pelvic inlet, $c=$ length of the pelvic outlet, and d=length of the sacrum (Fig. 2). We used these parameters in further analyses. 
Table 1 Patient characteristics

\begin{tabular}{|c|c|c|c|c|}
\hline \multirow[t]{2}{*}{ Variables } & \multirow[t]{2}{*}{ All $(n=136)$} & \multicolumn{2}{|l|}{ All $(n=136)$} & \multirow[t]{2}{*}{$p$ value } \\
\hline & & $\mathrm{AL}:-(n=115)$ & $\mathrm{AL}:+(n=21)$ & \\
\hline AL: $-/+$ & $115 / 21(84.6 / 15.4)$ & & & \\
\hline Sex: Female/Male & $55 / 81(40.4 / 59.6)$ & $52 / 63(45.2 / 54.8)$ & $3 / 18(14.3 / 85.7)$ & 0.016 \\
\hline Age $\dagger$ & $68.0[60.8,74.0]$ & $68.0[61.0,74.0]$ & $65.0[59.0,69.0]$ & 0.134 \\
\hline $\mathrm{BMI} \dagger$ & $21.4[19.5,23.7]$ & $21.5[19.4,23.9]$ & $21.1[20.7,23.4]$ & 0.964 \\
\hline Section: $\mathrm{Ra} / \mathrm{Rb}$ & $60 / 76(44.1 / 55.9)$ & $53 / 62(46.1 / 53.9)$ & $7 / 14(33.3 / 66.7)$ & 0.399 \\
\hline $\mathrm{NLR} \dagger$ & $2.4[1.8,3.4]$ & $2.3[1.8,3.3]$ & $2.9[2.4,3.4]$ & 0.075 \\
\hline $\mathrm{LMR} \dagger$ & $5.1[3.5,6.3]$ & $5.2[3.6,6.4]$ & $4.9[3.2,5.7]$ & 0.293 \\
\hline $\mathrm{Alb} \dagger$ & $4.2[3.9,4.5]$ & $4.2[3.9,4.5]$ & $4.1[3.7,4.4]$ & 0.242 \\
\hline Stoma: $-/+$ & $84 / 52(61.8 / 38.2)$ & $68 / 47(59.1 / 40.9)$ & $16 / 5(76.2 / 23.8)$ & 0.217 \\
\hline Drain: -/+ & $72 / 64(52.9 / 47.1)$ & $60 / 55(52.2 / 47.8)$ & $12 / 9(57.1 / 42.9)$ & 0.856 \\
\hline Operation time $(\min ) \dagger$ & $348.5[298.8,453.2]$ & $339.0[295.0,436.0]$ & $445.0[369.0,489.0]$ & 0.037 \\
\hline Blood loss $(\mathrm{ml}) \dagger$ & $53.0[20.0,210.0]$ & $50.0[20.0,175.0]$ & $190.0[50.0,573.0]$ & 0.014 \\
\hline Tumor size $(\mathrm{mm}) \dagger$ & $35.0[22.0,50.0]$ & $33.0[20.0,50.0]$ & $60.0[40.0,70.0]$ & $<0.001$ \\
\hline Laparotomy: -/+ & $122 / 14(89.7 / 10.3)$ & $106 / 9(92.2 / 7.8)$ & $16 / 5(76.2 / 23.8)$ & 0.043 \\
\hline UICC-T factor & & & & 0.213 \\
\hline T0 & $1(0.7)$ & $1(0.9)$ & $0(0.0)$ & \\
\hline Tis & $2(1.5)$ & $2(1.7)$ & $0(0.0)$ & \\
\hline $\mathrm{T} 1$ & $33(24.3)$ & $31(27.0)$ & $2(9.5)$ & \\
\hline $\mathrm{T} 2$ & $36(26.5)$ & $32(27.8)$ & $4(19.0)$ & \\
\hline $\mathrm{T} 3$ & $60(44.1)$ & $46(40.0)$ & $14(66.7)$ & \\
\hline $\mathrm{T} 4$ & $4(2.9)$ & $3(2.6)$ & $1(4.8)$ & \\
\hline UICC-stage & & & & 0.137 \\
\hline 0 & $1(0.7)$ & $1(0.9)$ & $0(0.0)$ & \\
\hline I & $61(44.9)$ & $56(48.7)$ & $5(23.8)$ & \\
\hline II & $16(11.8)$ & $12(10.4)$ & $4(19.0)$ & \\
\hline III & $40(29.4)$ & $33(28.7)$ & $7(33.3)$ & \\
\hline IV & $18(13.2)$ & $13(11.3)$ & $5(23.8)$ & \\
\hline $\begin{array}{l}\text { Neoadjuvant treatment*: } \\
-/+\end{array}$ & $124 / 12(91.2 / 8.8)$ & $104 / 11(90.4 / 9.6)$ & 20/1 (95.2/4.8) & 0.691 \\
\hline Lateral pelvis $(\mathrm{mm}) \dagger$ & $141.0[135.0,146.0]$ & $141.0[136.0,146.0]$ & $142.0[132.0,144.0]$ & 0.400 \\
\hline Sacrum $(\mathrm{mm}) \dagger$ & $123.0[114.0,133.2]$ & $123.0[114.0,132.5]$ & $130.0[119.0,142.0]$ & 0.029 \\
\hline Pelvic inlet $(\mathrm{mm}) \dagger$ & $115.0[105.0,122.0]$ & $114.0[105.0,121.5]$ & $115.0[109.0,123.0]$ & 0.545 \\
\hline Pelvic outlet $(\mathrm{mm}) \dagger$ & $89.0[84.0,96.2]$ & $89.0[84.0,98.0]$ & $91.0[83.0,94.0]$ & 0.411 \\
\hline
\end{tabular}

Values in parentheses are percentages; $\dagger$, median [interquartile range]; *, Neoadjuvant treatment includes neoadjuvant chemotherapy/chemoradiotherapy

$A L$ anastomotic leakage; BMI body mass index; NLR neutrophil-lymphocyte ratio; LMR lymphocytemonocyte ratio; Alb serum albumin; Tis tumor in situ

\section{Definition of anastomotic leakage}

AL was detected based on the following clinical signs: discharge of pus or stool from the abdominal drain, presence of peritonitis with a high fever, tachycardia, abdominal pain, tenderness, or severe inflammation. The presence of an abscess, fluid collection, or free air surrounding the anastomotic site was checked for using CT to assess the presence of AL if any leak was suspected. However, asymptomatic AL was difficult to consider, as we did not perform contrast enemas routinely.

\section{Statistical analyses}

The continuous and categorical variables were expressed as median values (with interquartile range [IQR]) and frequencies, respectively. For the comparisons of variables between the non-AL and AL groups, the Mann-Whitney $U$ test was conducted for continuous variables, and the Chi squared test or Fisher's exact test was used for categorical variables. A receiver operating characteristic (ROC) curve analysis using logistic regression was used to determine the cut-off values based on the point closest to $(0,1)$ criterion for each 
continuous variable. To identify the protective/risk factors for $\mathrm{AL}$, logistic regression analyses were performed. Variables were included in Firth's bias-reduced multiple logistic regression analysis with the stepwise Akaike's Information Criterion (AIC) variable selection method when a $p$ value $<0.20$ was observed in the univariate analysis. The confidence intervals and $p$ values for each factor were calculated by the Wald method.

All statistical analyses were performed using $\mathrm{R}$ language (R Core Team URL https://www.R-project.org/, Vienna, Austria). The logistic regression, ROC curve analysis, variable selection based on AIC, and Firth's bias-reduced multiple logistic regression were conducted using stats::glm, pROC::cords [20], stats::glm, and logistf:logistf functions, respectively. A $p$ value $<0.05$ was considered statistically significant.

\section{Results}

\section{Patient characteristics}

Table 1 shows the characteristics of the patients in the study. In total, 136 patients underwent LAR with DST or handsewn anastomosis, including 81 (59.6\%) males and 55 (40.4\%) females. The median age was 68.0 years (IQR, 60.8-74.0 years) and their median. The median BMI was $21.4 \mathrm{~kg} / \mathrm{m}^{2}$ (IQR, $19.5-23.7 \mathrm{~kg} / \mathrm{m}^{2}$ ). Sixty patients (44.1\%) and 76 patients (55.9\%) had $\mathrm{Ra}$ and $\mathrm{Rb}$ cancer, respectively. Twenty-one patients (15.4\%) developed AL, including 18 males and 3 females. The median BMI was $21.1 \mathrm{~kg} / \mathrm{m}^{2}$ (IQR, $\left.20.7-23.4 \mathrm{~kg} / \mathrm{m}^{2}\right)$; 7 of them (33.3\%) had Ra cancer, and 14 (66.7\%) had Rb cancer. We performed re-operation on 17 patients $(81.0 \%)$. We constructed a covering stoma and performed intraabdominal lavage and drainage in 16 of those 17 patients. Four of the five patients with covering stomas were treated using drainage. However, we performed reoperation with intraabdominal lavage and drainage on the remaining patient. There were 4 patients (19.0\%) with $\mathrm{AL}$ who did not need re-operation and were treated by drainage with an abdominal drain. The median post-surgery time until hospital discharge was 44 days (range 14-89 days). There were no deaths related to AL in this study. Among the 136 patients, 52 (38.2\%) underwent construction of a covering stoma, and 14 (10.3\%) underwent laparotomy. Five of those 14 patients developed AL.

\section{AL with or without a diverting stoma}

We stratified patients based on the construction of a stoma, with the results, as shown in Table 2. Among the patients without stomas $(n=84)$, sex $(p=0.006)$, operation time $(p<0.001)$, blood loss $(p=0.024)$, and tumor size $(p=0.005)$ were the factors that showed significant differences between the AL $(-)(n=68)$ and $\mathrm{AL}(+)(n=16)$ patients. Furthermore, Ra cancer was more frequent in $\mathrm{AL}$ $(-)$ patients, while $\mathrm{Rb}$ cancer was more frequent in $\mathrm{AL}(+)$ patients $(p=0.051)$. Among patients who underwent construction of a stoma $(n=52)$, there were significant differences in intraoperative blood loss $(p=0.033)$, tumor size $(p=0.027)$, laparotomy $(p=0.004)$, UICC-stage $(p=0.015)$, and sacrum factors $(p=0.044)$ between AL $(-)(n=47)$ and $\mathrm{AL}(+)$ patients $(n=5)$.

\section{Univariate and multivariate analyses}

Finally, we checked for an association between the construction of a stoma and AL. Table 3 shows the results of univariate and multivariate logistic regression analyses. Firth's bias-reduced multiple logistic regression analyses with the stepwise AIC variable selection method identified the variables of age ( $\geq 67$ years), Alb ( $\geq 4 \mathrm{~g} / \mathrm{dl}$ ), and stoma ( + ) as
Fig. 2 Measurements of pelvic dimensions. The four parameters were as follows: $a=$ length of the lateral pelvis, $b=$ length of the pelvic inlet, $\mathrm{c}=$ length of the pelvic outlet, and $\mathrm{d}=$ length of the sacrum
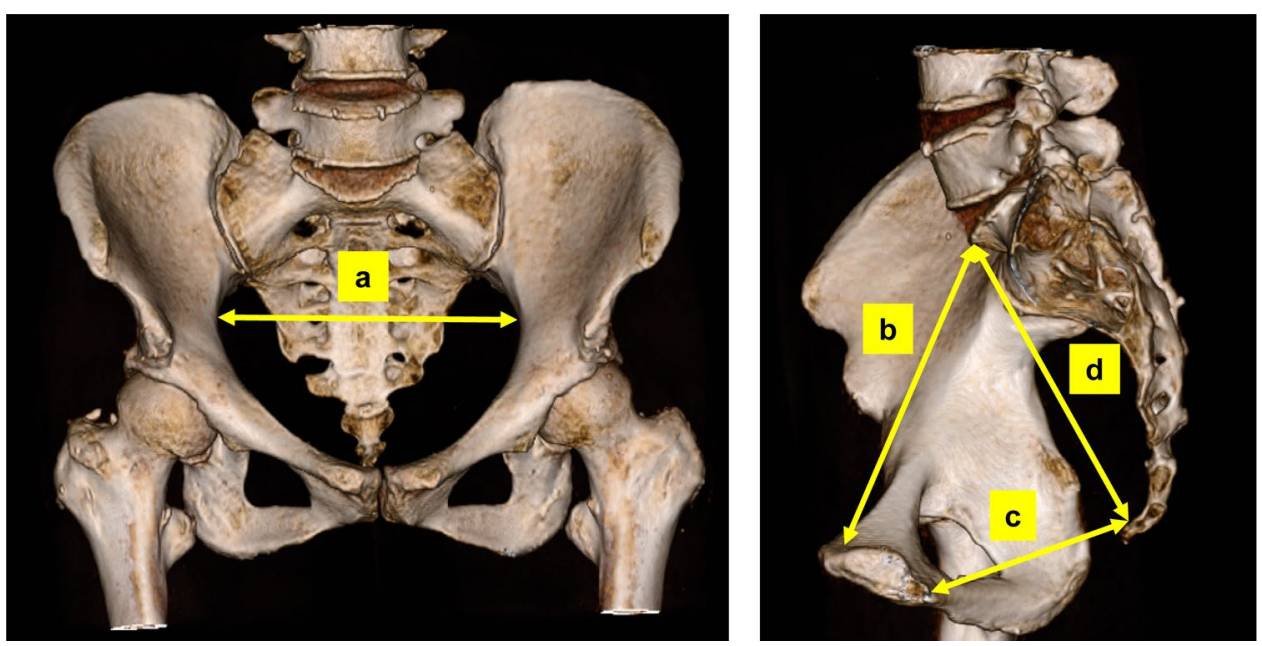
Table 2 Patient characteristics stratified by stoma construction

\begin{tabular}{|c|c|c|c|c|c|c|}
\hline \multirow[t]{2}{*}{ Variables } & \multicolumn{2}{|l|}{ Stoma: $-(n=84)$} & \multirow[t]{2}{*}{$p$ value } & \multicolumn{2}{|l|}{ Stoma: $+(n=52)$} & \multirow[t]{2}{*}{$p$ value } \\
\hline & $\mathrm{AL}:-(n=68)$ & $\mathrm{AL}:+(n=16)$ & & $\mathrm{AL}:-(n=47)$ & $\mathrm{AL}:+(n=5)$ & \\
\hline Sex: female/male & $37 / 31(54.4 / 45.6)$ & 2/14 (12.5/87.5) & 0.006 & 15/32 (31.9/68.1) & $1 / 4(20.0 / 80.0)$ & 1 \\
\hline Age $\dagger$ & $68.0[59.0,75.2]$ & $65.5[59.5,69.2]$ & 0.198 & $68.0[63.0,71.9]$ & $65.0[59.0,68.0]$ & 0.446 \\
\hline $\mathrm{BMI} \dagger$ & $21.1[19.2,22.9]$ & $21.4[20.7,23.4]$ & 0.396 & $22.5[20.2,25.5]$ & $20.7[18.4,21.1]$ & 0.352 \\
\hline Section: $\mathrm{Ra} / \mathrm{Rb}$ & $46 / 22(67.6 / 32.4)$ & $6 / 10(37.5 / 62.5)$ & 0.051 & $7 / 40(14.9 / 85.1)$ & $1 / 4(20.0 / 80.0)$ & 1 \\
\hline $\mathrm{NLR} \dagger$ & $2.4[1.8,3.6]$ & $2.9[2.4,3.2]$ & 0.257 & $2.3[1.7,3.0]$ & $3.4[2.6,3.9]$ & 0.210 \\
\hline $\mathrm{LMR} \dagger$ & $5.3[3.6,6.6]$ & $4.9[3.2,5.5]$ & 0.415 & $4.8[3.7,6.2]$ & $4.9[3.2,5.7]$ & 0.555 \\
\hline $\mathrm{Alb} \dagger$ & $4.3[4.0,4.5]$ & $4.2[3.7,4.4]$ & 0.382 & $4.2[3.8,4.4]$ & $3.8[3.7,3.9]$ & 0.297 \\
\hline Drain: $-/+$ & $36 / 32(52.9 / 47.1)$ & $7 / 9(43.8 / 56.2)$ & 0.701 & $24 / 23(51.1 / 48.9)$ & $5 / 0(100.0 / 0.0)$ & 0.059 \\
\hline Operation time $(\min ) \dagger$ & $304.5[273.8,339.0]$ & $414.5[320.8,468.2]$ & $<0.001$ & $466.0[398.5,619.0]$ & $445.0[419.0,489.0]$ & 0.733 \\
\hline Blood loss $(\mathrm{ml}) \dagger$ & $30.0[15.0,60.0]$ & $112.5[41.2,540.0]$ & 0.024 & $160.0[38.5,230.0]$ & $1100.0[190.0,2365.0]$ & 0.033 \\
\hline Tumor size $(\mathrm{mm}) \dagger$ & $30.0[20.0,50.0]$ & $55.0[38.8,66.2]$ & 0.005 & $35.0[25.0,50.0]$ & $70.0[55.0,80.0]$ & 0.027 \\
\hline Laparotomy: -/+ & $61 / 7(89.7 / 10.3)$ & $14 / 2(87.5 / 12.5)$ & 0.679 & $45 / 2(95.7 / 4.3)$ & $2 / 3(40.0 / 60.0)$ & 0.004 \\
\hline UICC-T factor & & & 0.373 & & & 0.338 \\
\hline $\mathrm{T} 0$ & $0(0.0)$ & $0(0.0)$ & & $1(2.1)$ & $0(0.0)$ & \\
\hline Tis & $1(1.5)$ & $0(0.0)$ & & $1(2.1)$ & $0(0.0)$ & \\
\hline $\mathrm{T} 1$ & $22(32.4)$ & $2(12.5)$ & & $9(19.1)$ & $0(0.0)$ & \\
\hline $\mathrm{T} 2$ & $18(26.5)$ & $4(25.0)$ & & $14(29.8)$ & $0(0.0)$ & \\
\hline $\mathrm{T} 3$ & $25(36.8)$ & $9(56.2)$ & & $21(44.7)$ & $5(100.0)$ & \\
\hline $\mathrm{T} 4$ & $2(2.9)$ & $1(6.2)$ & & $1(2.1)$ & $0(0.0)$ & \\
\hline UICC-stage & & & 0.400 & & & 0.015 \\
\hline 0 & $1(1.5)$ & $0(0.0)$ & & $0(0.0)$ & $0(0.0)$ & \\
\hline I & $35(51.5)$ & $5(31.2)$ & & $21(44.7)$ & $0(0.0)$ & \\
\hline II & $9(13.2)$ & $2(12.5)$ & & $3(6.4)$ & $2(40.0)$ & \\
\hline III & $18(26.5)$ & $6(37.5)$ & & $15(31.9)$ & $1(20.0)$ & \\
\hline IV & $5(7.4)$ & $3(18.8)$ & & $8(17.0)$ & $2(40.0)$ & \\
\hline Neoadjuvant treatment*: $-/+$ & $68 / 0(100.0 / 0.0)$ & $16 / 0(100.0 / 0.0)$ & 1 & $36 / 11(76.6 / 23.4)$ & $4 / 1(80.0 / 20.0)$ & 1 \\
\hline Lateral pelvis $(\mathrm{mm}) \dagger$ & $142.0[137.0,148.0]$ & $138.5[131.8,144.8]$ & 0.168 & $140.0[134.0,144.0]$ & $142.0[132.0,144.0]$ & 0.804 \\
\hline Sacrum $(\mathrm{mm}) \dagger$ & $122.5[114.0,129.2]$ & $128.0[118.8,140.0]$ & 0.131 & $123.0[113.0,137.0]$ & $145.0[130.0,151.0]$ & 0.044 \\
\hline Pelvic inlet $(\mathrm{mm}) \dagger$ & $113.0[105.0,119.2]$ & $115.5[107.2,123.2]$ & 0.412 & $115.0[105.5,122.5]$ & $115.0[114.0,115.0]$ & 0.828 \\
\hline Pelvic outlet $(\mathrm{mm}) \dagger$ & $90.0[84.0,99.0]$ & $89.0[82.8,94.5]$ & 0.408 & $88.0[84.0,97.5]$ & $91.0[86.0,92.0]$ & 0.963 \\
\hline
\end{tabular}

Values in parentheses are percentages; $\dagger$, median [interquartile range]; *, Neoadjuvant treatment includes neoadjuvant chemotherapy/chemoradiotherapy

$A L$ anastomotic leakage, $B M I$ body mass index, $N L R$ neutrophil-lymphocyte ratio, $L M R$ lymphocyte-monocyte ratio, Alb serum albumin, Tis tumor in situ

protective factors and sex (male), NLR $(\geq 2.4)$, LMR $(\geq 5.3)$, operation time ( $\geq 373 \mathrm{~min})$, blood loss $(\geq 105 \mathrm{ml})$, tumor size $(\geq 41 \mathrm{~mm})$, and pelvic inlet size $(\geq 113 \mathrm{~mm})$ as risk factors for AL. The area under the curve (AUC) was 0.95 (95\% confidence interval [CI]: 0.91-0.99), suggesting that these identified factors were strongly associated with AL (Fig. 3). Among the pre- and intraoperative factors, the construction of a covering stoma (stoma + , odds ratio [OR] 0.05, 95\% CI [21] 0.01-0.26) was found to be a strong protective factor, and the operation time ( $\geq 373 \mathrm{~min}$, OR $9.83,95 \% \mathrm{CI}$ 1.98-48.86), intraoperative blood loss ( $\geq 105 \mathrm{ml}$, OR 5.05, 95\% CI 1.05-24.23), and pelvic inlet diameter ( $\geq 113 \mathrm{~mm}$,
OR 5.07, 95\% CI 1.13-22.66) were identified as strong risk factors for AL from the multivariate analysis.

\section{Discussion}

In our study, the overall rate of $\mathrm{AL}$ occurrence was $15.4 \%$ (21/136). In patients with stomal construction, the rate of AL occurrence was $9.6 \%(5 / 52)$, and in those without a stoma, the AL rate was $19.0 \%$ (16/84). In our institute, the rate of AL was nearly $10 \%$ in patients with covering stomas, which was markedly higher than that recorded in the 


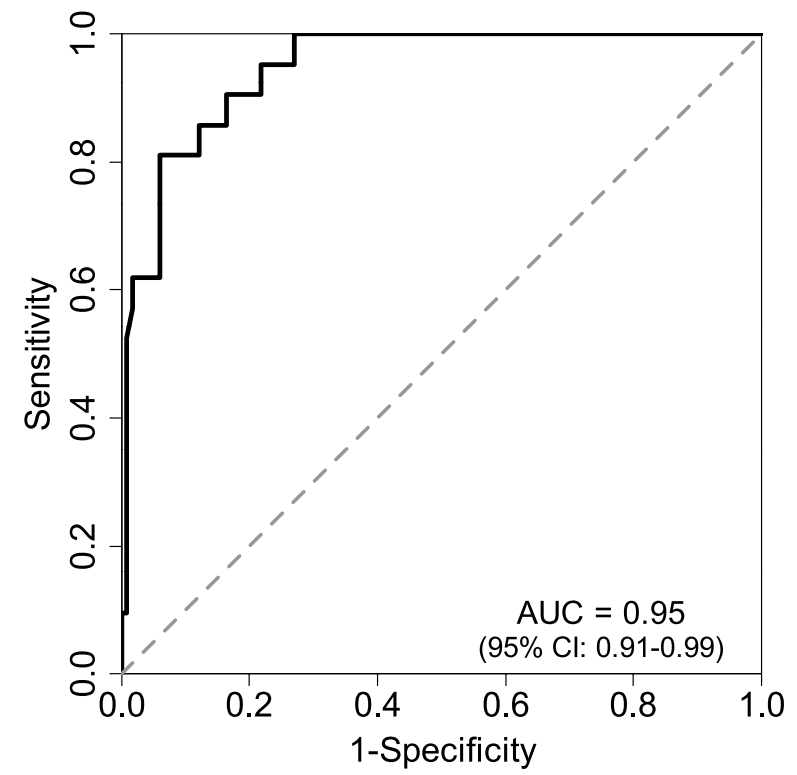

Fig. 3 Model evaluation for AL. Firth's bias-reduced multiple logistic regression analysis with the stepwise AIC variable selection method. The AUC was 0.95 (95\% CI: 0.91-0.99), suggesting that the identified factors were strongly associated with AL. $A L$ anastomotic leakage, $N L R$ neutrophil-lymphocyte ratio, $L M R$ lymphocyte-monocyte ratio, Alb serum albumin, AIC Akaike's Information Criterion, AUC area under the curve, $C I$ confidence interval
Japanese database [22]. Regarding the consecutive patients that we evaluated in this study, there were 14 patients with laparotomy who developed AL significantly more frequently than laparoscopic procedure ( $p=0.043)$, and among them, 3 of the 5 patients with covering stomas had AL. Regarding cases without laparotomy, there were 16 patients out of $122(13.1 \%)$ and 2 out of 47 (4.3\%) who had AL among all patients and those with stomas, respectively.

As we performed laparoscopic surgery in most cases, there were some cases with bulky tumors, and resection of these large lesions was difficult. There might have been some bias in the decision to construct a stoma, since it depended on the intraoperative findings. In other words, surgeons constructed a stoma in serious cases, so some reports found no relationship between $\mathrm{AL}$ and stoma construction [23, 24]. Our comparisons (Table 1) and a univariate analysis (Table 3 ) of the association between $\mathrm{AL}$ and stoma construction did not show any statistical significance. However, the multivariate logistic regression analysis showed that the construction of a covering stoma was a strong protective factor when other variables were held constant.

Figure 3 suggests that the AUC was 0.95 (95\% CI 0.91-0.99), and the analyzed factors (i.e., sex, age, NLR,
Table 3 Results of a logistic regression analysis

\begin{tabular}{|c|c|c|c|c|c|c|c|c|}
\hline \multirow[t]{3}{*}{ Variables } & \multicolumn{4}{|c|}{ Univariate analysis } & \multicolumn{4}{|c|}{ Multivariate analysis $\dagger$} \\
\hline & \multirow[t]{2}{*}{ OR } & \multicolumn{2}{|l|}{$95 \% \mathrm{CI}$} & \multirow[t]{2}{*}{$p$ value } & \multirow[t]{2}{*}{ OR } & \multicolumn{2}{|l|}{$95 \% \mathrm{CI}$} & \multirow[t]{2}{*}{$p$ value } \\
\hline & & Lower & Upper & & & Lower & Upper & \\
\hline Sex: Male & 4.95 & 1.38 & 17.74 & 0.014 & 3.85 & 0.92 & 16.09 & 0.065 \\
\hline Age $($ years $) \geq 67$ & 0.43 & 0.17 & 1.11 & 0.081 & 0.39 & 0.11 & 1.44 & 0.157 \\
\hline $\mathrm{BMI} \geq 21$ & 1.03 & 0.40 & 2.62 & 0.958 & & & & \\
\hline Section: $\mathrm{Rb}$ & 1.71 & 0.64 & 4.55 & 0.283 & & & & \\
\hline $\mathrm{NLR} \geq 2.4$ & 4.80 & 1.52 & 15.15 & 0.007 & 3.42 & 0.73 & 16.00 & 0.119 \\
\hline $\mathrm{LMR} \geq 5.3$ & 0.53 & 0.20 & 1.40 & 0.199 & 2.90 & 0.62 & 13.58 & 0.175 \\
\hline $\mathrm{Alb} \geq 4$ & 0.39 & 0.15 & 1.01 & 0.051 & 0.29 & 0.07 & 1.16 & 0.081 \\
\hline Stoma: + & 0.45 & 0.16 & 1.32 & 0.146 & 0.05 & 0.01 & 0.26 & $<0.001$ \\
\hline Drain: + & 0.82 & 0.32 & 2.09 & 0.675 & & & & \\
\hline Operation time $(\min ) \geq 373$ & 4.51 & 1.63 & 12.52 & 0.004 & 9.83 & 1.98 & 48.86 & 0.005 \\
\hline Blood loss $(\mathrm{ml}) \geq 105$ & 3.75 & 1.40 & 10.04 & 0.009 & 5.05 & 1.05 & 24.23 & 0.043 \\
\hline Tumor size $(\mathrm{mm}) \geq 41$ & 5.49 & 1.97 & 15.30 & 0.001 & 2.66 & 0.70 & 10.05 & 0.149 \\
\hline Laparotomy: + & 3.68 & 1.09 & 12.38 & 0.035 & & & & \\
\hline UICC-T: (T3, T4) vs. (T0, Tis, T1, T2) & 3.37 & 1.22 & 9.30 & 0.019 & & & & \\
\hline UICC-stage: (III, IV) vs. (0, I, II) & 2.00 & 0.78 & 5.13 & 0.149 & & & & \\
\hline Lateral pelvis $(\mathrm{mm}) \geq 142$ & 1.24 & 0.49 & 3.15 & 0.648 & & & & \\
\hline Sacrum $(m m) \geq 129$ & 2.81 & 1.09 & 7.26 & 0.033 & & & & \\
\hline Pelvic inlet $(\mathrm{mm}) \geq 113$ & 2.06 & 0.75 & 5.70 & 0.162 & 5.07 & 1.13 & 22.66 & 0.034 \\
\hline Pelvic outlet $(\mathrm{mm}) \geq 91$ & 1.65 & 0.65 & 4.20 & 0.293 & & & & \\
\hline
\end{tabular}

†Variables were included in the Firth's bias-reduced multiple logistic regression analysis with the stepwise AIC variable selection method when a $p$-value $<0.20$ was observed in the univariate analysis

AIC Akaike's Information Criterion, BMI body mass index, $N L R$ neutrophil-lymphocyte ratio, $L M R$ lymphocyte-monocyte ratio, Alb serum albumin, Tis tumor in situ, $O R$ odds ratio, $C I$ confidence interval 
LMR, Alb, stoma, operation time, blood loss, tumor size, and pelvic inlet) were strongly associated with AL. A further analysis showed that the operation time ( $\geq 373 \mathrm{~min}$ ), intraoperative blood loss ( $\geq 105 \mathrm{~min}$ ), and pelvic inlet diameter ( $\geq 113 \mathrm{~mm}$ ) were strong risk factors for AL (Table 3). Several risk factors were reported based on preoperative and intraoperative findings. A few studies identified risk factors for AL by measuring the patients' pelvic dimensions using preoperative imaging examinations. According to those studies, the preoperative and intraoperative risk factors included the sex, operation time, and amount of intraoperative blood loss [13, 14].

Several studies have concluded that male sex is a risk factor for AL [24, 25]. Similarly, the findings of our analysis also indicated that males were at a significant risk of developing AL. Furthermore, the operation time and intraoperative blood loss were also reported as major risk factors for $\mathrm{AL}$ in many studies $[13,26]$. Our analysis provided results that were comparable to these previous findings. The pelvic index was also reported as a risk factor in a previous study [15]. Tsuruta et al. reported that a smaller ratio of the mesorectum to the depth of the cavity of the lesser pelvis was associated with an increased risk of AL. We also observed that a larger pelvic inlet size $(\geq 113 \mathrm{~mm})$ was a risk factor when other variables were held constant. From our analysis considering other clinical confounding factors, we did not detect any confounders. The univariate analysis might have been affected by other confounding factors. However, the multivariate analysis reduced these possible effects by other confounding factors. Therefore, regarding the pelvic index, the significant risk factors differed between the univariate and multivariate analyses. A longer sacrum and pelvic inlet were significant risk factors for AL in univariate and multivariate analyses, respectively (Table 3 ).

Initially, we measured several pelvic dimensions (short lengths of the lateral pelvis, anteroposterior diameter, and sacrum) under the hypothesis that males, with their narrow pelvis, might have a higher risk of AL than females. However, our analysis showed that a longer pelvic inlet was a significant risk factor for AL. This result may be explained by the presence of a deeper pelvis making it difficult to perform the operation. In other words, surgeons considered that the narrow pelvis during the operation was due not only to the skeletal structure but also the soft tissue, such as the muscles, intestinal size, and amount of mesenteric adipose tissue.

This study is limited by its nature as a retrospective record review performed at a single institution. In the future, our findings should be confirmed in more cases.

\section{Conclusion}

In conclusion, the results obtained after analyzing the data of 136 patients with rectal cancer suggested that the construction of a covering stoma was a possible protective factor. The results further indicated that a longer operation time, higher intraoperative blood loss, and larger pelvic inlet dimensions were possible risk factors for $\mathrm{AL}$ after low anterior resection in patients with rectal cancer. Further prospective studies may help clarify the pertinent factors predicting postoperative morbidity in patients with rectal cancer.

Acknowledgements The authors thank Masao Nakajima MD, PhD, Yuta Kimura MD, Kou Kanesada MD, and the members of the Department of Gastroenterological, Breast and Endocrine Surgery at Yamaguchi University Graduate School of Medicine for their participation in this study. We would also like to thank Editage (www.editage.com) for the English language editing.

Author contributions NS, SH and $\mathrm{HN}$ took part in conception and design. NS, SY, ST, YS, YT, MI, ST, TUand HN were involved in acquisition of the data. NS and YN were involved in analysis and interpretation of the data. NS and YN contributed to drafting of the first version of manuscript. All of the authors agreed to be accountable for all aspects of the work.

Funding No funding was received for this study

Availability of data and material The datasets generated during and/or analyzed during the current study are available from the corresponding author on reasonable request

\section{Compliance with ethical standards}

Conflict of interest The authors declare that they have no conflict of interest.

Ethics approval This study was performed in accordance with the ethical standards laid down in the 1964 Declaration of Helsinki Ethical and its later amendments. The study protocol and legal and social implications were approved by the Ethics Committee of Yamaguchi University Hospital (H28-186).

Consent to participate All study participants provided written informed consent prior to their inclusion in the study.

Consent for publication All of the authors were involved in final approval.

Open Access This article is licensed under a Creative Commons Attribution 4.0 International License, which permits use, sharing, adaptation, distribution and reproduction in any medium or format, as long as you give appropriate credit to the original author(s) and the source, provide a link to the Creative Commons licence, and indicate if changes were made. The images or other third party material in this article are 
included in the article's Creative Commons licence, unless indicated otherwise in a credit line to the material. If material is not included in the article's Creative Commons licence and your intended use is not permitted by statutory regulation or exceeds the permitted use, you will need to obtain permission directly from the copyright holder. To view a copy of this licence, visit http://creativecommons.org/licenses/by/4.0/.

\section{References}

1. Heald RJ, Husband EM, Ryall RD. The mesorectum in rectal cancer surgery-the clue to pelvic recurrence? Br J Surg. 1982;69:613-6.

2. Heald RJ, Moran BJ, Ryall RD, Sexton R, MacFarlane JK. Rectal cancer: the Basingstoke experience of total mesorectal excision, 1978-1997. Arch Surg. 1998;133:894-9.

3. Matsuda T, Yamashita K, Hasegawa H, Oshikiri T, Hosono M, Higashino N, et al. Recent updates in the surgical treatment of colorectal cancer. Ann Gastroenterol Surg. 2018;2:129-36.

4. van der Pas MH, Haglind E, Cuesta MA, Furst A, Lacy AM, Hop WC, et al. Laparoscopic versus open surgery for rectal cancer (COLOR II): short-term outcomes of a randomised, phase 3 trial. Lancet Oncol. 2013;14:210-8.

5. Kang SB, Park JW, Jeong SY, Nam BH, Choi HS, Kim DW, et al. Open versus laparoscopic surgery for mid or low rectal cancer after neoadjuvant chemoradiotherapy (COREAN trial): short-term outcomes of an open-label randomised controlled trial. Lancet Oncol. 2010;11:637-45.

6. Guillou PJ, Quirke P, Thorpe H, Walker J, Jayne DG, Smith AM, et al. Short-term endpoints of conventional versus laparoscopicassisted surgery in patients with colorectal cancer (MRC CLASICC trial): multicentre, randomised controlled trial. Lancet. 2005;365:1718-26.

7. Boyce SA, Harris C, Stevenson A, Lumley J, Clark D. Management of low colorectal anastomotic leakage in the laparoscopic era: more than a decade of experience. Dis Colon Rectum. 2017;60:807-14.

8. Ihnat P, Gunkova P, Peteja M, Vavra P, Pelikan A, Zonca P. Diverting ileostomy in laparoscopic rectal cancer surgery: high price of protection. Surg Endosc. 2016;30:4809-16.

9. Hain E, Maggiori L, Manceau G, Zappa M. Prost a la Denise J, Panis Y: persistent asymptomatic anastomotic leakage after laparoscopic sphincter-saving surgery for rectal cancer: can diverting stoma be reversed safely at 6 months? Dis Colon Rectum. 2016;59:369-76.

10. Mirnezami A, Mirnezami R, Chandrakumaran K, Sasapu K, Sagar P, Finan P. Increased local recurrence and reduced survival from colorectal cancer following anastomotic leak: systematic review and meta-analysis. Ann Surg. 2011;253:890-9.

11. Bell SW, Walker KG, Rickard MJ, Sinclair G, Dent OF, Chapuis $\mathrm{PH}$, et al. Anastomotic leakage after curative anterior resection results in a higher prevalence of local recurrence. Br J Surg. 2003;90:1261-6.

12. Braunschmid T, Hartig N, Baumann L, Dauser B, Herbst F. Influence of multiple stapler firings used for rectal division on colorectal anastomotic leak rate. Surg Endosc. 2017;31:5318-26.
13. Konishi T, Watanabe T, Kishimoto J, Nagawa H. Risk factors for anastomotic leakage after surgery for colorectal cancer: results of prospective surveillance. J Am Coll Surg. 2006;202:439-44.

14. Makela JT, Kiviniemi H, Laitinen S. Risk factors for anastomotic leakage after left-sided colorectal resection with rectal anastomosis. Dis Colon Rectum. 2003;46:653-60.

15. Tsuruta A, Tashiro J, Ishii T, Oka Y, Suzuki A, Kondo H, et al. Prediction of anastomotic leakage after laparoscopic low anterior resection in male rectal cancer by pelvic measurement in magnetic resonance imaging. Surg Laparosc Endosc Percutan Tech. 2017;27:54-9.

16. Watanabe T, Miyata H, Konno H, Kawai K, Ishihara S, Sunami E, et al. Prediction model for complications after low anterior resection based on data from 33,411 Japanese patients included in the National Clinical Database. Surgery. 2017;161:1597-608.

17. Zur Hausen G, Grone J, Kaufmann D, Niehues SM, Aschenbrenner K, Stroux A, et al. Influence of pelvic volume on surgical outcome after low anterior resection for rectal cancer. Int J Colorectal Dis. 2017;32:1125-35.

18. Yoo RN, Kim HJ. Total neoadjuvant therapy in locally advanced rectal cancer: role of systemic chemotherapy. Ann Gastroenterol Surg. 2019;3:356-67.

19. Sammour T, Chang GJ. Lateral pelvic lymph node dissection and radiation treatment for rectal cancer: mutually exclusive or mutually beneficial? Ann Gastroenterol Surg. 2018;2:348-50.

20. Robin X, Turck N, Hainard A, Tiberti N, Lisacek F, Sanchez J-C, et al. pROC: an open-source package for $\mathrm{R}$ and $\mathrm{S}+$ to analyze and compare ROC curves. BMC Bioinform. 2011;12:77.

21. Sciuto A, Merola G, De Palma GD, Sodo M, Pirozzi F, Bracale UM, et al. Predictive factors for anastomotic leakage after laparoscopic colorectal surgery. World J Gastroenterol. 2018;24:2247-60.

22. Matsubara N, Miyata H, Gotoh M, Tomita N, Baba H, Kimura W, et al. Mortality after common rectal surgery in Japan: a study on low anterior resection from a newly established nationwide largescale clinical database. Dis Colon Rectum. 2014;57:1075-81.

23. Shiomi A, Ito M, Maeda K, Kinugasa Y, Ota M, Yamaue H, et al. Effects of a diverting stoma on symptomatic anastomotic leakage after low anterior resection for rectal cancer: a propensity score matching analysis of 1,014 consecutive patients. J Am Coll Surg. 2015;220:186-94.

24. Hamabe A, Ito M, Nishigori H, Nishizawa Y, Sasaki T. Preventive effect of diverting stoma on anastomotic leakage after laparoscopic low anterior resection with double stapling technique reconstruction applied based on risk stratification. Asian J Endosc Surg. 2018;11:220-6.

25. Shinji S, Ueda Y, Yamada T, Koizumi M, Yokoyama Y, Takahashi G, et al. Male sex and history of ischemic heart disease are major risk factors for anastomotic leakage after laparoscopic anterior resection in patients with rectal cancer. BMC Gastroenterol. 2018;18:117.

26. Fukada M, Matsuhashi N, Takahashi T, Imai H, Tanaka Y, Yamaguchi K, et al. Risk and early predictive factors of anastomotic leakage in laparoscopic low anterior resection for rectal cancer. World J Surg Oncol. 2019;17:178.

Publisher's Note Springer Nature remains neutral with regard to jurisdictional claims in published maps and institutional affiliations. 